\title{
SIMULATION OF TWO HIGH PRESSURE DISTRIBUTION NETWORK OPERATION IN ONE-NETWORK CONNECTION
}

\begin{abstract}
SORIN PERJU - Lecturer, PhD, Technical University of Civil Engineering of Bucharest, Faculty of Hydrotechnics, e-mail: sorin.perju@utcb.ro

MĂDĂLIN MIHAILOVICI - Associated Professor, PhD, Technical University of Civil Engineering of Bucharest, Faculty of Hydrotechnics, e-mail: madalin.mihailovici@apanovabucuresti.ro

IOANA STĂNESCU - Assistant Professor, PhD, Technical University of Civil Engineering of Bucharest, Faculty of Hydrotechnics, e-mail: ioana_ais@yahoo.com

Abstract: The programs developed by the water supply system operators in view of metering the branches and reducing the potable water losses from the distribution network pipes lead to the performance reassessment of these networks. As a result the energetic consumption of the pumping stations should meet the accepted limits. An essential role in the evaluation of the operation parameters of the network performance is played by hydraulic modeling, by means of which the network performance simulation can be done in different scenarios. The present article describes the concept of two high-pressure network coupling. These networks are supplied by two repumping stations, in which the water flows were drastically reduced due to the present situation.
\end{abstract}

Keywords: network distribution, pumping stations, numerical model, EPANET

\section{Introduction}

Designed in different stages and completed on the basis of knowledge, technologies, equipment and materials established for the respective stages, the water distribution network in operation was designed and built in a period of time when the energy cost was a factor of reduced weighting in the exploitation costs. Today, the energy price tends to comply with energy prices of the EU countries and the energy in the potable water price is a considerable weighting factor. Within the distribution networks, the pumping and repumping stations and the house water supply plants are the greatest energy consumers that secure the pressure and the outflow to the user branch, with a major influence in the management of the potable water pumping and distribution process [1].

The progress registered in water pumping engineering, as well as the advanced technology in the control and tracking of the hydraulic system operating parameters, consisting of pumping station - distribution network, allowed for exploitation performance, and new operating facilities in the system. The remote control and the automation of the pumping - repumping stations are the main elements, that, once implemented, have created a favorable environment for a certain and profound knowledge of the operation parameters, giving the possibility for research studies like: the analysis and balance sheet of energy consumption, the quantities of the pumped and distributed water, the lifetime of the pumps, the system dysfunctions.

In this context, the optimization of the energy costs of the integrated water distribution systems aiming at reducingpower consumption, represents a big issue, that is, a need for energetic and functional optimization of the water distribution system, for both new systems and the operating ones, followed by the elaboration of some hydraulic models and high-performance software for better solving the water distribution systems analysis and design, as well as the measures and solutions for the susbtantial reduction of water loss in the system. 
The performance optimization of both the water distribution network and the associated pumping stations, is done by using a modern and adequate mathematical software, thus being possible to establish numerical models on the basis of which the exploitation scenarios in different configurations can be analysed. The results of the analysis and the draw up reports represent the basic elements in the final decision for the rehabilitation and the endowment of the water distribution network and the pumping stations.

\section{High pressure water distribution network in Tei-Colentina district}

Located in the Northern - Eastern side of the town, the district Tei-Colentina utilises a water distribution system developed along time, in stages, according to the area urban extention. Therefore, together with the construction of apartment buildings, it became necessary to work out new water distribution networks, in order to ensure the parameters needed for potable water in the GF+8 ... GF+10 buildings. Thus, three pumping stations were built, in different stages between the '70s and the '80s : Teiul Doamnei, Petricani and Lacul Tei, located in the areas shown in Fig. 1.

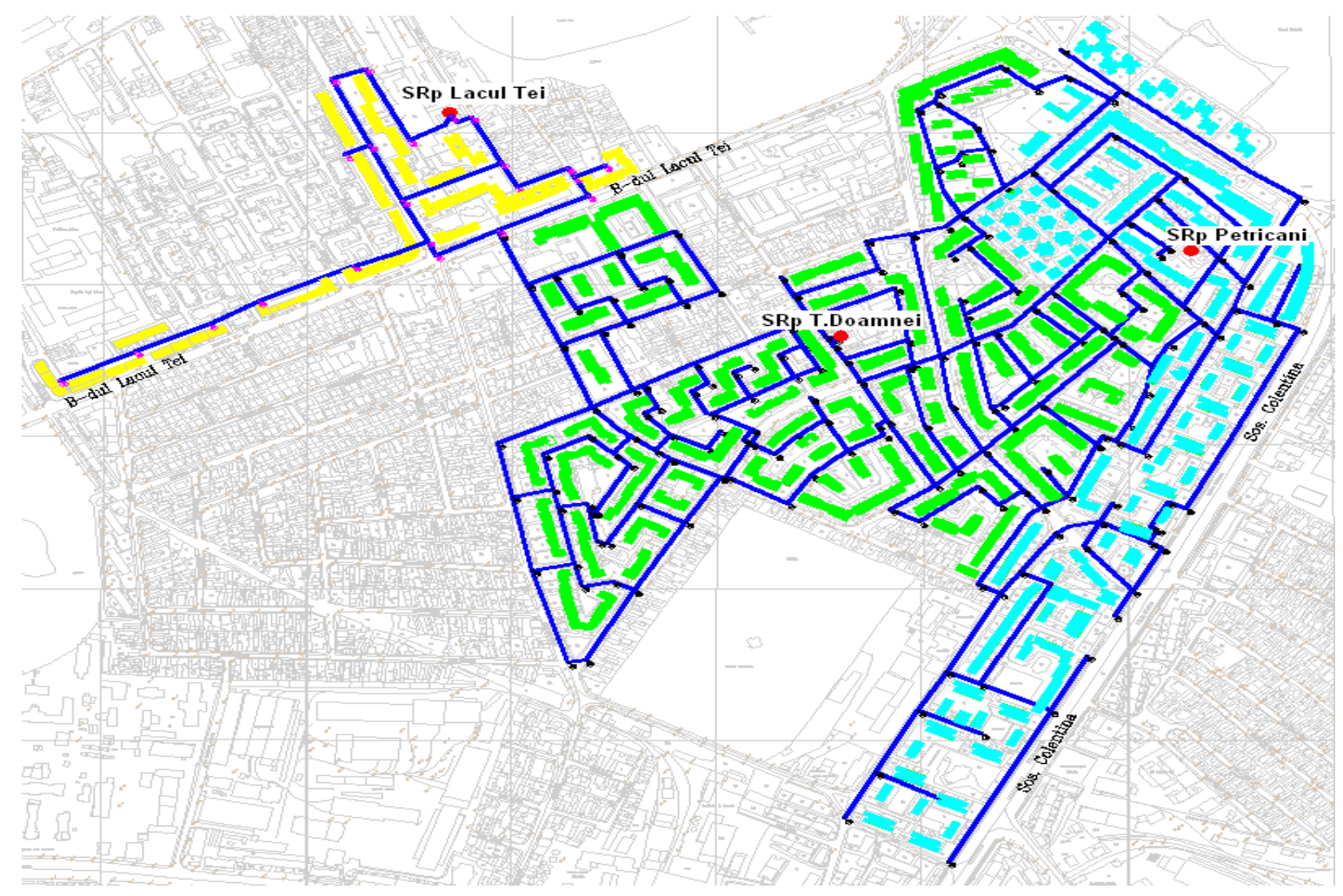

Fig. 1 - The location of the pumping stations in Tei-Colentina district

Initially, Teiul Doamnei and Petricani pumping stations were designed and built to operate as classical pumping stations sucking from a series of reservoirs and discharging in a high pressure pipe network, that serves a housing district with a working lift of GF+8 ... GF+10. Lacul Tei pumping station has an inlet directed in the low pressure network and an outlet directed to the high pressure network associated to this station. The endowment of the stations consists of Romanian pumps models NDS, DN / TN, activated with fixed speed [2].

The control of the working conditions for the 3 pumping stations was done by the sequential start up and shut down of the the pumps, whose control was performed by the operation personnel, that intended to correlate two parameters: the pressure in the outlet and the water table in the inlet reservoirs.

In time, the operating conditions of the pumping stations went through major changes, that led to the modification of the working parameters, in such a way that the parameters of the pumping 
stations had significant differences compared to the nominal parameters of the pumps, that is, they registered high energetic consumptions.

Thereby, a first step was developed in the '90s, when due to the socio-economic changes, the water consumption was reduced, the pressure in the low pressure network went up, therefore at Petricani and Teiul Doamnei pumping stations, the inlet reservoirs were put out of service, and the pump inlet was directed to the low pressure network. This was the operation pressure that was used in the re-pumping stations (that varried between 15-25 mCA). Apparently, this way of exploitation seemed to bring an advantage, but in reality, due to the pump parameters, that were $\mathrm{Q}=360 \mathrm{mc} / \mathrm{h}$ and $\mathrm{H}=60 \mathrm{~m}$, it led to the operation of the partially open outlet valve, so that it should not exceed the maximum accepted pressure in the pipes (6 bar). The pumps worked at low capacity and low efficiency, and registered high energy consumption.

The second major stage in the exploitation condition change was the rehabilitation of the stations based on extensive measurements of the working parameters, by the replacement of the fixed speed pumps with variable speed pumps. Additionally, a study about the high pressure networks served by these repumping stations was performed; the study involved the shut down of Petricani repumping station and the consumers taking over Teiul Doamnei repumping station. Thereby, starting with November 2004 and up to the present, the branches of the high pressure network in the area are being served by the repumping stations Teiul Doamnei and Lacul Tei, stations that are completely rehabilitated and automatic, resulting in substantial energy savings, as it is shown in the diagram of Fig.2, based on the annual registered consumption.

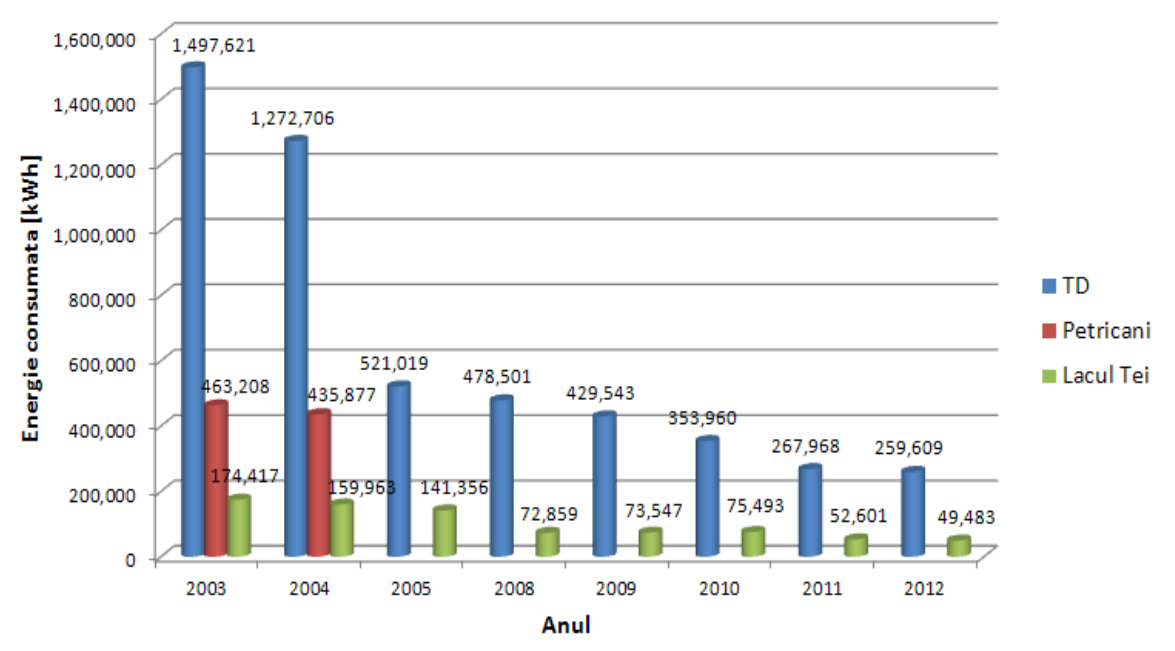

Fig. 2 - Energetic consumption evolution in transfer pumping stations

It can be observed that the moment the transfer pump stations were equiped with variable speed pumps (year 2005), the annual energetic consumption was substantial reduced, reaching less than a third from the consumption levels registered when the stations operated with fixed speed pumps.

However, the diagram in Fig. 2, shows that the yearly reduction in energetic consumption follows a continous down trend, for both re-pumping stations. This fact is completely normal as long as:

- firstly, immediately after the rehabilitation and automation of the pumps, the water company started a complete program for diminishing water losses in the distribution networks;

- secondly, all the branches need to be registered, thus avoiding the lump sum tax consumption.

Compared to the year 2004, the pumped water flows dropped, resulting in only one reduced speed pump operation in the re-pumping station. Moreover, there is a need for new directions for the two neighbouring networks and for the analysis of the possibilities for developing Teiul Doamnei transfer pumping station and the decommission of Lacul Tei pumping station. 


\section{Hydraulic modeling of the high-pressure water distribution network in Tei-Colentina area (district)}

For accomplishing the hydraulic model of the high pressure distribution networks and the analysis and assay of the these networks in different operation scenarios, the interface of the program EPANET 2.0 was used; the program was developed by the Environment Protection Agency, USA, and is designed for hydraulic calculations and for water quality analysis in the distribution networks [3]. EPANET is designed as a research instrument for the correction of the misunderstandings regarding the water flow in the pipe pressure network. It can be used for different applications in analyzing the distribution networks.

The phases in developing the network model were:

- The precise definition of the network configuration according to the two areas in terms of physical elements (pipeline hubs, pipes, diameters, geodesic head, conjunctions, etc.);

- The assignment of the consumption in the conjunction network (the flows were calculated based on the average flows pumped by the two stations in 2012);

- The implementation of the distribution network model for the whole study area, by the identification of the conjunctions between the networks (closed valve);

- Introducing the characteristic curves of the pumps in Teiul Doamnei station $(\mathrm{H}=\mathrm{f}(\mathrm{Q})$ and $\eta=f(Q))$ in the program;

- The calibration of the network model, issued on the basis of the energy consumption year 2012;

- The performance of the hydraulic calculations in view of optimizing the distribution network on the supposition that Teiul Doamnei station is operating alone.

The final structure of the hydraulic model comprises 236 conjunctions and 283 pipes, an open valve between the two sub-networks and a re-pumping station endowed with variable speed pumps.

The simulation of the transfer pumping station that provides the needed flow and pressure in the network junctions was accomplished by using the characteristic curves in the EPANET program (Fig. 3). In order to simulate the hourly consumption variation during a day, the EPANET program allows the user to enter the input of the hourly variation coefficients using the instruction Pattern Editor. The hourly variation flow diagram for each conjunction, related with the average flow, is shown in Fig. 4, according to the variation curve consumption for a large town [4].

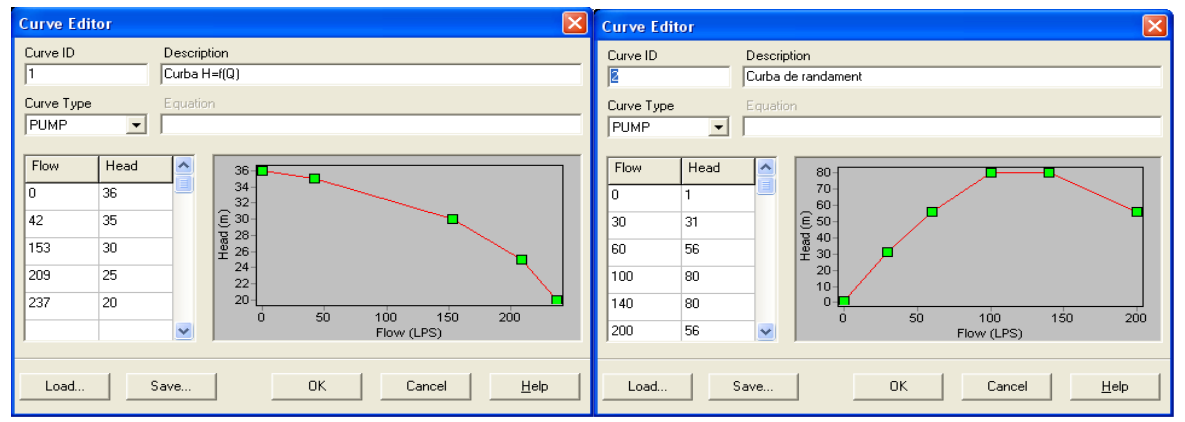

Fig. 3- The pump and yield diagrams

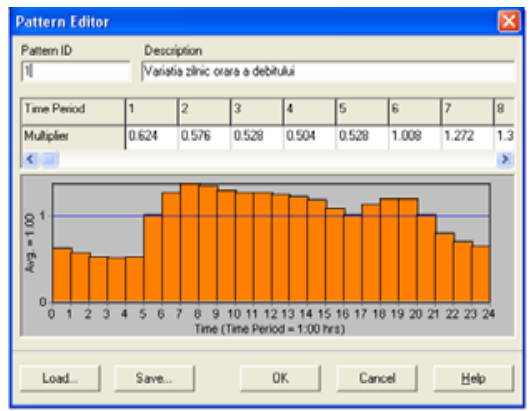

Fig. 4 - The diagram for the hourly variation consumption 


\section{Hydraulic calculations and results for optimizing the high-pressure distribution networks in Tei-Colentina district}

The first stage in the hydraulic calculation for the high pressure distribution networks for TeiColentina area, consisted of the water distribution network simulation considering the decommission of the transfer pumping station Lacul Tei. For that purpose, in the first step of the system operation, we tested the network capacity, by simulating Teiul Doamnei transfer pumping station as a constant level reservoir that continously ensures: a piezometric head of 50 $\mathrm{m}$, to mirror the present operation ( 5 bars in the pumping station discharge pipe), and the open isolating valve between the two subnetworks. In the exploitation phase where the water flows supplied by Teiul Doamnei pumping station vary between $55 \mathrm{l} / \mathrm{s}$ and $151 \mathrm{l} / \mathrm{s}$ (Fig. 5), the values recorded for the pressure variation in junction 216 (which belong to the subnetworks served by Lacul Tei repumping station and which is the most hydraulically unfavoured), do not decrease below 47,5 mWc (Fig. 6). This value is high enough to provide the water supply service for an apartment building of GF+10.

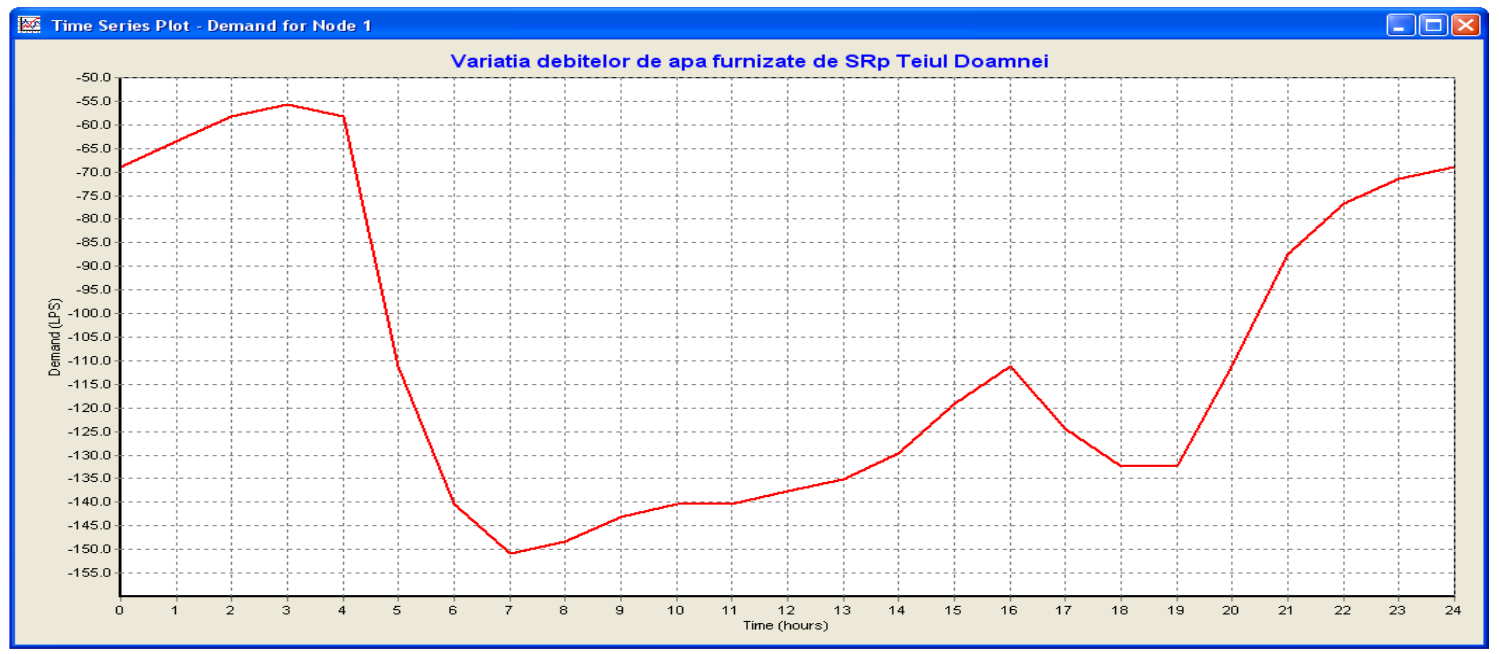

Fig. 5 - The hourly water flow variation pumped by the Teiul Doamnei repumping station

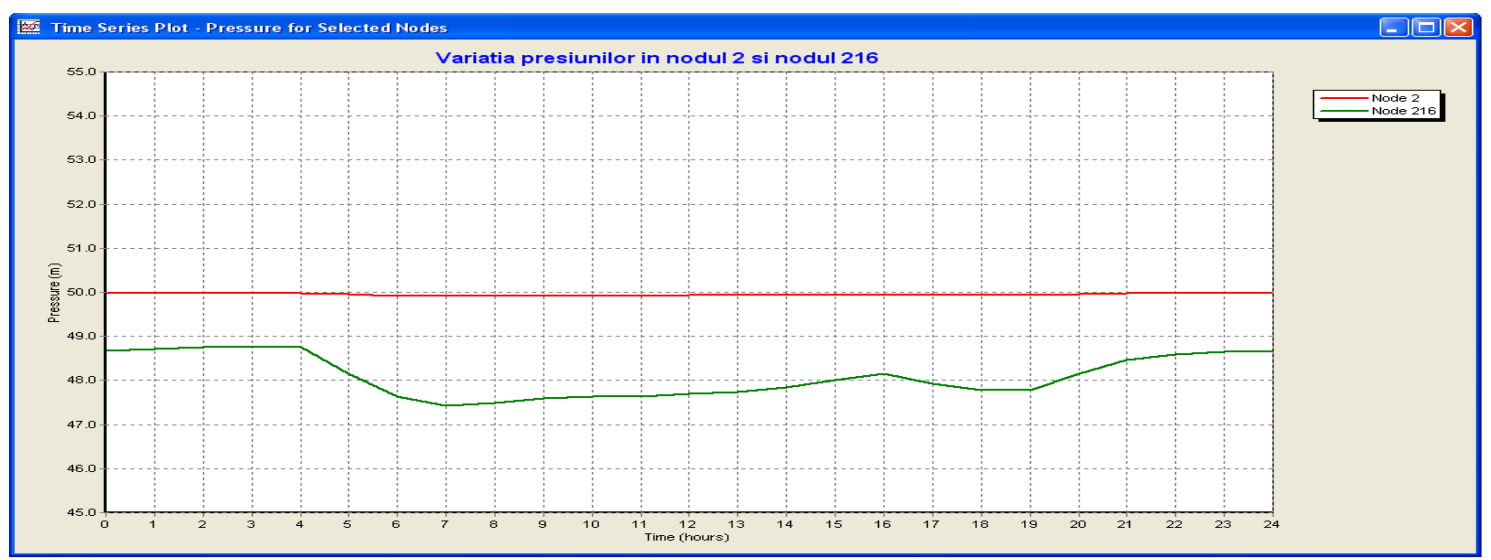

Fig. 6 - The hourly pressure variation in the junctions 2 (Teiul Doamnei RPS) and 216 (apartment building of $\mathrm{GF}+10)$

The variation of the water flow in the distribution network, supplied at present by Lacul Tei RPS is shown in Fig. 7, where it is determined that these values range between 6,7 l/s and $18 \mathrm{l} / \mathrm{s}$. Considering that the best value for the monthly average flow in Lacul Tei repumping station was 15,17 l/s in 2012, the tasks of Lacul Tei repumping station can be overtaken by Teiul Doamnei repumping station, without affecting the actual operation service. 


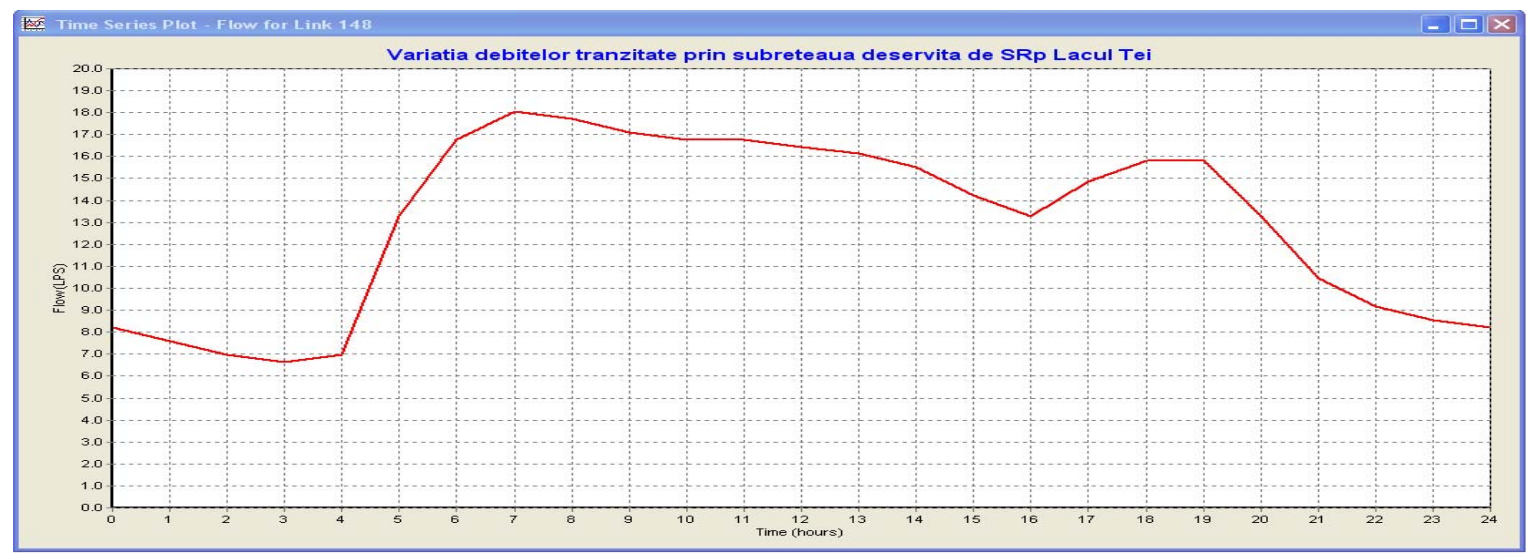

Fig. 7 - Hourly variation of the flows in the sub-network supplied currently by Lacul Tei RPS

The configuration of the high pressure network and of the distribution in the network conjunctions at 7 AM ( the hour of maximal consumption) is shown in Fig 8, in the hypothesis of Teiul Doamnei repumping station operation so that the piezometric head achieves a pressure of $50 \mathrm{mWc}$. It can be observed that in no conjunctions the pressure falls below $47 \mathrm{mWc}$.

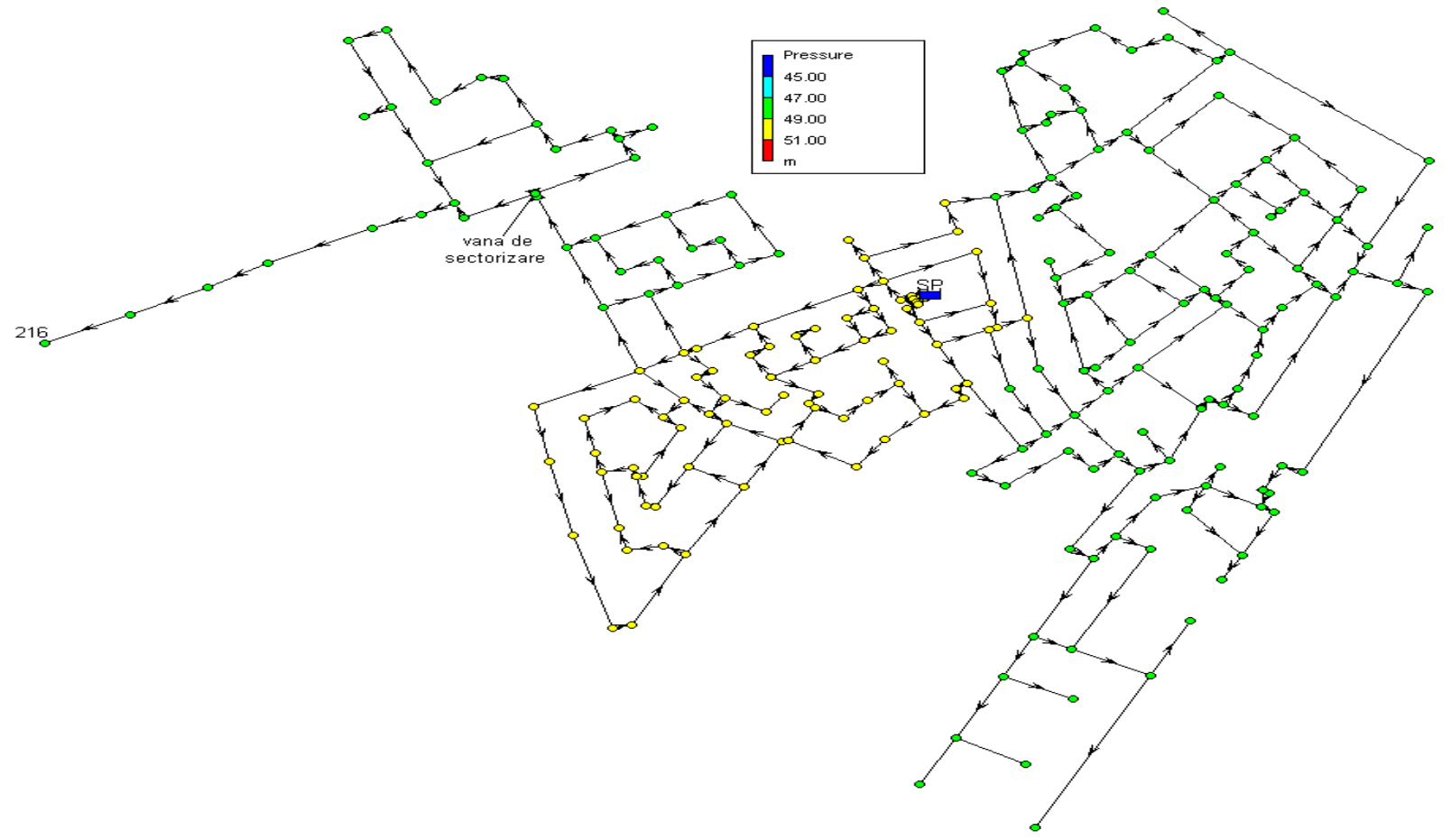

Fig. 8 - The pressure variation in the Tei-Colentina high pressure network

In the second phase of the hydraulic calculation, in order to find out the energetic consumption in t Teiul Doamnei repumping station and considering the shutdown of Lacul Tei repumping station, we obtained the simulation of the high pressure distribution network for Teiul Doamnei repumping station, endowed with variable speed pumps. This simulates the actual station control, disposed for a $50 \mathrm{mWc}$ pressure daily operating in the outlet pipe. In order to describe this operation step, EPANET program enables the user to enter some basic compilations, so that the variation of the speed pump can be simulated. These basic compilations are meant to maintain $50 \mathrm{mWc}$ in the outlet pipe and to modify the pump speed according to the changes in the hourly consumption, followed by the variation of the characteristic diagram of the pump. The speed was modified by up to $70 \%$ from the nominal speed, with a variation step of 2 . In this way, 62 courses were written, where the increase and the decrease of the pump speed were described (Fig. 8 represents an example of the first and the last two instructions). 
Therefore, having introduced the characteristic diagram $H=f(Q)$ and the yield diagram $\eta=f(Q)$, we equipped the station with 4 pumps. Afterwards, we calibrated the model as to operate, using the Teiul Doamnei repumping station and the high pressure network that it currently supplies, Fig. 9.

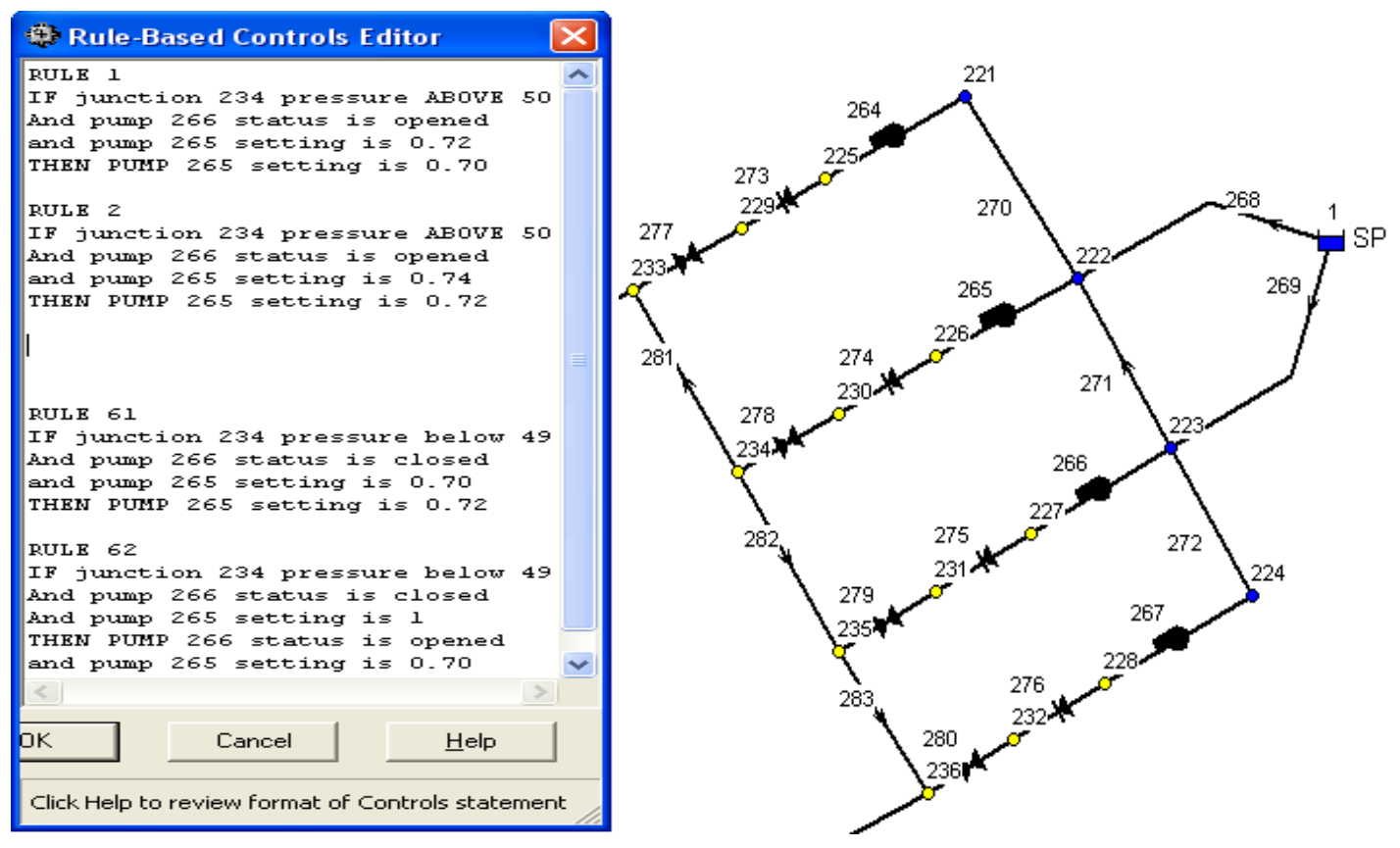

Fig. 9 - Exploitation scenarios and the configuration of Teiul Doamnei repumping station

Within the exploitation data registered for October, 2012 (the period with the highest energy consumption and the highest pumped flow), the calibration was accomplished and it is shown in Fig.10.

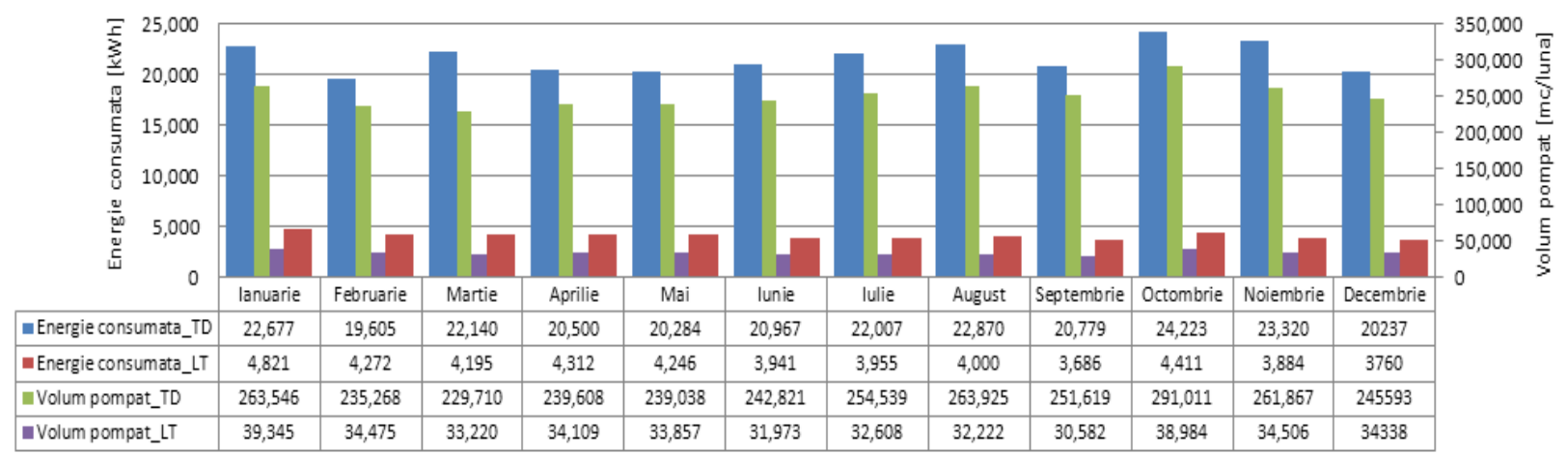

Fig. 10 - The input and the pumped flow in Teiul Doamnei RPS and Lacul Tei RPS

Hydraulic calculations were performed within the calibrated model, on the supposition that Teiul Doamnei repumping station supplies the water flow needed for the customers connected to the high pressure distribution network previously serviced by Lacul Tei repumping station. This operation was possible by opening the isolation valve with a diameter Dn of $250 \mathrm{~mm}$ located between the two sub-networks.

We obtained results from the simulation of exploiting the network, given that the values of the pumped flow are the same as the ones we had simulated for the station operating like a constantlevel reservoir. The results highlighted that the daily hourly variation of the pressure in the most unfavoured conjunction (conjunction 216) ranged between $45.5 \mathrm{mWc}$ and $49.5 \mathrm{mWc}$, values sufficient for the water supply of a GF+10 apartment building, as it can be observed in the diagram obtained from simulating the operation of the network. 


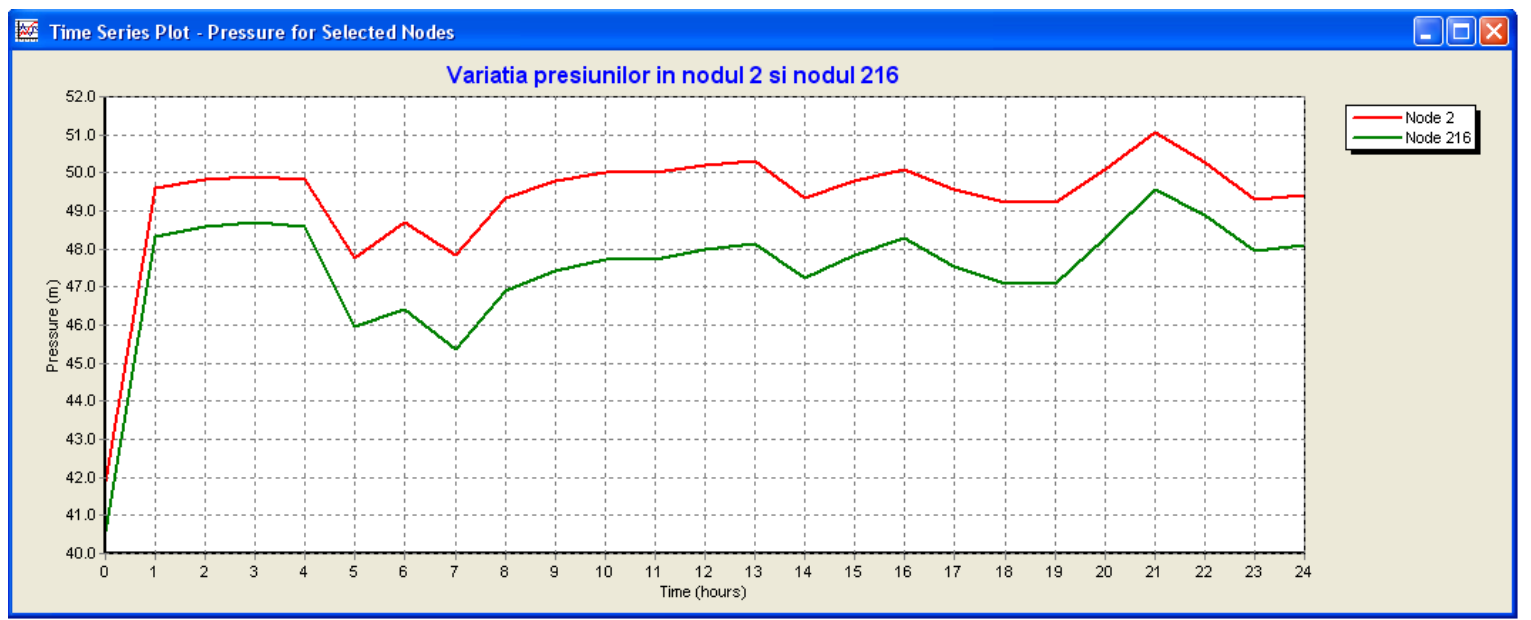

Fig. 11 - Hourly pressure variation in conjunctions 2 (Teiul Doamnei RPS) and 216 (apartment building GF+10)

The hourly average power demand registered in Teiul Doamnei repumping station in this configuration and with variable speed, is $34,1 \mathrm{~kW}$. It results that the repumping station will have a yearly power demand of $34.1 \times 24 \times 365=298716 \mathrm{kWh}$, by operating in these conditions. The values for the power demand after the simulation in the given conditions are listed in the diagram below, Fig.12.

\begin{tabular}{|c|c|c|c|c|c|c|}
\hline \multicolumn{6}{|c|}{ 氖 Energy Report } & - $\square$ \\
\hline Table Chart & & & & & & \\
\hline Pump & $\begin{array}{l}\text { Percent } \\
\text { Utilization }\end{array}$ & $\begin{array}{l}\text { Average } \\
\text { Efficiency }\end{array}$ & $\begin{array}{c}\mathrm{Kw}-\mathrm{hr} \\
/ \mathrm{m} 3\end{array}$ & $\begin{array}{l}\text { Average } \\
\text { Kwatts }\end{array}$ & $\begin{array}{l}\text { Peak } \\
\text { Kwatts }\end{array}$ & $\begin{array}{l}\text { Cost } \\
\text { /day }\end{array}$ \\
\hline 264 & 0.00 & 0.00 & 0.00 & 0.00 & 0.00 & 0.00 \\
\hline 265 & 100.00 & 73.04 & 0.09 & 34.10 & 45.46 & 122.75 \\
\hline 266 & 0.00 & 0.00 & 0.00 & 0.00 & 0.00 & 0.00 \\
\hline 267 & 0.00 & 0.00 & 0.00 & 0.00 & 0.00 & 0.00 \\
\hline Total Cost & & & & & & 122.75 \\
\hline Demand Charge & & & & & & 0.00 \\
\hline
\end{tabular}

Fig. 12 - The consumptions for Teiul Doamnei RPS

\section{Conclusions}

In the study case associated to Tei-Colentina district, the analysis of the optimisation of the distribution network was performed exclusively for the high pressure networks, at present supplied by Teiul Doamnei and Lacul Tei repumping stations.

The concept for elaborating the study regarding the rehabilitation of the high pressure network, started from the need to decrease the power demand, in addition to improving the operating hydraulic parameters of the pumps in Teiul Doamnei repumping station. The study was needed due to the fact that after the station was rehabilitated in 2005 (by replacing the pumps and automating the station), the water company started a project/plan for the water loss decrease. The program was developed along with the one for registering branches resulting in significant decreases of the pumped water flows in the distribution network.

Following this approach in decreasing the water losses and knowing the consumption levels, the pumps in the repumping station work at different parameters compared to the initial ones. 
Therefore, a solution implying no suplimentary costs and no changes in operation is the extension of the influence area of Teiul Doamnei repumping station, that could overtake the capacity of Lacul Tei repumping station, thus producing two great advantages:

- The pumps in Teiul Doamnei repumping station will work at parameters that are almost equal to the nominal ones, improving the pump capacity;

- The shutdown of Lacul Tei repumping station would save $10.376 \mathrm{kWh}$ yearly (if we consider 2012 as a reference year), not taking into account the maintenance costs for the above station.

From the present analysis and based on the simulations accomplished with the EPANET program, it appears that these operating conditions are the most fesable, mainly due to the fact that Teiul Doamnei repumping station has enough capacity, considering that the station is endowed with 4 HS pumps GRUNDFOS (2 fixed speed pumps and 2 variable speed pumps), of which only a single pump is mainly used in the current operation.

The subject of the present article was presented within the Scientific and Technical Conference „Water Services and the New Energy Challenges”, June, 2013.

\section{References}

[1]. Perju S. (2006). The monitoring and hydraulic optimising of the water distribution networks for rehabilitation, PhD Thesis, Bucharest.

[2]. Anton A., Perju S., et.al. (2003). Measurements of the hydroenergetic parameters and network assays for 24 repumping station. Hydraulic Study, Bucharest.

[3]. Rossman, L. EPANET 2 Users Manual. (2000) U.S. Environmental Protection Agency, 600/R-00/057, Cincinnati, $\mathrm{OH}$.

[4]. ***, STAS 1343-66, Hourly variation coefficients for the daily water consumption diagram in the inhabited areas.

[5]. Perju, S., Mihailovici, M. (2013). Optimizarea functionarii retelelor de inalta presiune din zona Tei Colentina, Scientific and Technical Conference „Water Services and the new energy challanges”. 